\title{
Association Between Non-erosive Reflux Disease and High Risk of Obstructive Sleep Apnea in Korean Population
}

\author{
Chan Ran You, Jung Hwan Oh, ${ }^{*}$ Minji Seo, Hye Yeon Lee, Hyonsoo Joo, Sung Hoon Jung, Sang Haak Lee and Myung-Gyu Choi
}

Department of Internal Medicine, The Catholic University of Korea, College of Medicine, Seoul, Korea

\section{Background/Aims}

Obstructive sleep apnea is becoming more important in gastroesophageal reflux disease (GERD) patients. This study investigated the prevalence of high risk for obstructive sleep apnea in GERD patients in comparison with that in healthy controls using the Berlin Questionnaire. We also investigated the risk factors for obstructive sleep apnea in GERD patients.

\section{Methods}

We enrolled 1,007 subjects: 776 healthy controls, 115 individuals with erosive reflux disease, and 116 with non-erosive reflux disease. GERD was diagnosed and classified using endoscopy and a reflux questionnaire. The Berlin Questionnaire was used to evaluate obstructive sleep apnea.

\section{Results}

More patients in the GERD group (28.2\%) had higher risk for obstructive sleep apnea than healthy controls $(20.4 \%, P=$ 0.036). More patients with non-erosive disease $(32.8 \%)$ had higher risk for obstructive sleep apnea (OSA) than patients with erosive disease $(20.9 \%)$ and controls $(20.4 \%, P=0.010)$. On multivariate analysis, non-erosive disease was a high risk factor for obstructive sleep apnea (odds ratio [OR], 1.82; $P=0.011)$. Age $\geq 55$ years $(O R, 1.83 ; P<0.001)$ and a high body mass index $\left(\geq 25 \mathrm{~kg} / \mathrm{m}^{2}\right)(O R, 2.76 ; P<0.001)$ were also identified as risk factors. Nocturnal GERD was related to high risk for OSA in non-erosive disease patients $(O R, 2.97 ; P=0.019)$, but not in erosive disease patients.

\section{Conclusions}

High risk for OSA is more prevalent in GERD patients than in controls. Non-erosive reflux disease, age $\geq 55$, and a high BMI are associated with high risk for OSA.

(J Neurogastroenterol Motil 2014;20:197-204)

\section{Key Words}

Gastroesophageal reflux; Esophagitis; Sleep apnea, obstructive

Received: January 1, 2014 Revised: February 19, 2014 Accepted: February 23, 2014

(c) This is an Open Access article distributed under the terms of the Creative Commons Attribution Non-Commercial License (http://creativecommons. org/licenses/by-nc/3.0) which permits unrestricted non-commercial use, distribution, and reproduction in any medium, provided the original work is properly cited.

*Correspondence: Jung Hwan Oh, MD

Department of Internal Medicine, St. Paul's Hospital, College of Medicine, The Catholic University of Korea, 222 Banpo-daero, Seocho-gu, Seoul 137-701, Korea

Tel: +82-2-958-2114, Fax: +82-2-968-7250, E-mail: ojh@catholic.ac.kr

Financial support: None.

Conflicts of interest: None.

Author contributions: Chan Ran You and Jung Hwan Oh designed the study and drafted and revised the manuscript and approved the final version of the manuscript; Minji Seo, Hye Yeon Lee and Hyonsoo Joo collected and analyzed data; Sung Hoon Jung, Hye Yeon Lee and Myung-Gyu Choi supervised the study and extensively revised the manuscript.

ORCID: Chan Ran You, http://orcid.org/0000-0001-9384-0700; Jung Hwan Oh, http://orcid.org/0000-0002-9274-882X; Sung Hoon Jung, http://orcid.org/0000-0003-0303-7434. 


\section{Introduction}

Gastroesophageal reflux disease (GERD) is a very common disorder worldwide, and is classified into erosive reflux disease (ERD) and non-erosive reflux disease (NERD). In western countries, typical GERD symptoms such as heartburn and acid regurgitation occur in about $20 \%$ of adults. In Eastern Asia, the prevalence of GERD has increased gradually and was reported to be around $2.5-4.8 \%$ before 2005 but reached to $5.2-8.5 \%$ from 2005 to $2010 .^{1}$

GERD can coexist with variable extraesophageal manifestations such as non-cardiac chest pain, posterior laryngitis, respiratory complications, and sleep disturbance. The association between GERD and sleep disorders is controversial, even though a relationship between GERD and insomnia has been established. More recently, obstructive sleep apnea (OSA) is found to be an emerging sleep-related breathing disorder characterized by episodes of intermittent, partial, or complete obstruction of the upper airway. It causes transient awakening from sleep during the night.

One published study ${ }^{2}$ suggested GERD may be associated with OSA, but this is still being debated. Furthermore, in an epidemiologic survey, GERD patients with nocturnal symptoms were found to be at an increased risk of OSA. ${ }^{3}$ Patients with OSA may have an increased risk of GERD, as evidenced by the frequent findings of gastrointestinal symptoms, esophageal pH monitoring, and endoscopic findings of esophagitis. ${ }^{2,4}$

Therefore, the aim of this study was to compare the prevalence of high risk for OSA in patients with GERD and that in healthy controls to evaluate if there is an association between GERD and OSA. For this, we used the Berlin Questionnaire, a convenient and inexpensive tool, which has been widely used in the screening for the clinical evaluation of OSA. ${ }^{5}$ In addition, risk factors for OSA in GERD subjects were investigated.

\section{Materials and Methods}

\section{Subjects}

We enrolled 1,363 subjects who visited the gastrointestinal clinic and the health promotion center of St. Paul's Hospital of The Catholic University of Korea between March and October in 2009. Trained and certified clinicians performed the standard gastroduodenal endoscopic examination in all patients. Subsequently, all patients completed questionnaires for the evaluation of GERD and the Berlin questionnaire for OSA. We excluded 356 subjects who had a history of gastrointestinal surgery, peptic ulcer disease, gastroduodenal neoplasm, or other chronic systemic diseases requiring medical therapy. Peptic ulcer disease was observed in 183 patients, gastroduodenal neoplasm in 26 patients, and abnormal laboratory findings were reported in 23 patients. Eight patients were excluded because they had a history of gastrointestinal surgery, and the others were excluded for various miscellaneous reasons, including the presence of other medical disease or psychiatric disorders. Finally, 1,007 subjects were included in this study (Fig. 1). All subjects in the control group were participants from the health promotion center, while the subjects in the GERD group included all patients from the gastrointestinal clinic and a few participants from the health promotion center. The subjects of control group had no specific gastrointestinal symptoms and received endoscopic examination for screening. Using a questionnaire, we excluded participants with typical reflux symptoms from the control group. The study was approved by the institutional review board at our hospital (PC09ZZZZ0060).

\section{Questionnaires}

The reflux questionnaire has been designed to investigate a patient's gastroesophageal reflux symptoms and socio-demographic data and was completed by each subject. The questionnaire used was originally designed by the Mayo clinic for an epidemiological study and was then adapted for our study. ${ }^{6-9}$ The subjects were asked to respond to questions regarding the weekly frequency of typical reflux symptoms such as heartburn and acid regurgitation and to rate them on a scale of 1-5: (0) none, (1) less than once a month, (2) approximately once a month, (3) approximately once a week, (4) more than twice a week and (5) every day.

The Berlin questionnaire (BQ) has been validated as a tool for identifying patients who are at high risk for OSA with variations designed for different countries. ${ }^{10,11}$ The BQ includes 10 questions in 3 categories: 5 items about snoring severity in category 1, 4 items about wake-time sleepiness and tiredness in category 2 and history of hypertension or obesity in category $3 .^{12}$ Category 1 and 2 are positive when the total score reaches 2 points or more and category 3 is positive if the subject has a history of high blood pressure and/or BMI of more than $30 \mathrm{~kg} / \mathrm{m}^{2}$. High risk for OSA is defined as 2 or more positive categories, while low risk for OSA is defined as only one or none of the positive categories. All questionnaires were completed before diagnostic evaluation and administered by trained and certified staff. 


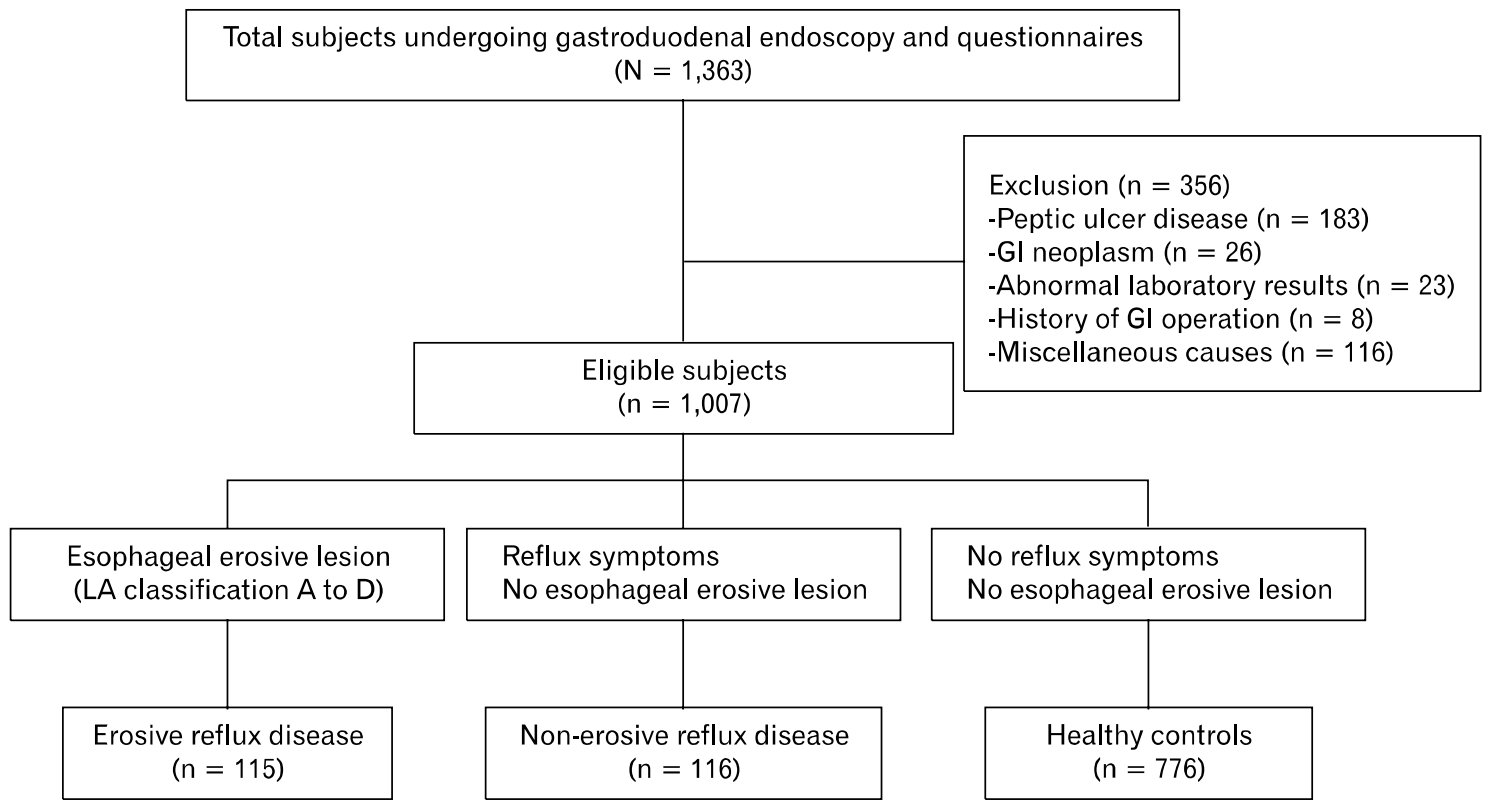

Figure 1. Flow chart of the protocol used to classify subjects in this study.

Table 1. Baseline Characteristics of the Study Subjects

\begin{tabular}{lrcc}
\hline & $\begin{array}{c}\text { GERD } \\
(\mathrm{n}=231)\end{array}$ & $\begin{array}{c}\text { Controls } \\
(\mathrm{n}=776)\end{array}$ & $P$-value \\
\hline Age (mean $\pm \mathrm{SD}, \mathrm{yr})$ & $55.1 \pm 9.1$ & $54.9 \pm 8.8$ & 0.767 \\
Sex (n [\%]) & & & 0.166 \\
$\quad$ Male & $100(43.3)$ & $297(38.3)$ & \\
Female & $131(56.7)$ & $479(61.7)$ & \\
BMI (mean $\left.\pm \mathrm{SD}, \mathrm{kg} / \mathrm{m}^{2}\right)$ & $23.9 \pm 2.8$ & $23.7 \pm 2.9$ & 0.501 \\
$<25$ & $158(68.4)$ & $536(69.1)$ & \\
$\geq 25$ & $73(31.6)$ & $240(30.9)$ & \\
Cigarette smoking (n [\%]) & $30(13.1)$ & $84(10.9)$ & 0.346 \\
Alcohol consumption (n [\%]) & $119(52.2)$ & $339(43.9)$ & 0.026 \\
Nocturnal GERD (n [\%]) & $54(23.4)$ & $32(4.1)$ & $<0.001$ \\
\hline
\end{tabular}

GERD, gastroesophageal reflux disease; BMI, body mass index.

\section{Disease Classification}

We described endoscopic findings for GERD according to the Los Angeles (LA) classification of esophagitis. ${ }^{13}$ ERD was defined as endoscopy findings indicating mucosal breaks at the gastroesophageal junction, classified as from $\mathrm{A}$ to $\mathrm{D}$ according to the LA classification. Patients who showed minimal change were excluded from the ERD group. The NERD group included patients who experienced typical GERD symptoms such as heartburn or acid regurgitation for more than once a week but did not experience erosive esophagitis. If a patient had symptoms but had minimal change at the gastroesophageal junction, then the patient was excluded from the ERD group and included in the NERD group. Controls had no GERD symptoms with normal endoscopic findings.

\section{Statistical Methods}

Patient's categorical data were presented as mean \pm standard deviation. Chi-square test or Fisher's exact test was applied to evaluate categorical variables. A $t$ test was used to evaluate continuous variables. Differences between GERD and controls were assessed using the Chi square test and t tests. Both univariate and multivariate analyses were performed to investigate risk factors for OSA (SAS system for Windows, version 9.2; SAS Institute, Cary, North Carolina, USA). The level of statistical significance was $P<0.05$ for all analyses.

\section{Results}

\section{Baseline Characteristics}

A total of 1,007 subjects were enrolled in this study (Fig. 1). The baseline demographic and clinical characteristics of all subjects are presented in Tables 1 and 2. There were no differences in age (55.1 \pm 9.1 vs. $54.9 \pm 8.8, P=0.767)$, sex (male, $43.3 \%$ vs. $38.3 \%, P=0.166)$, body mass index (BMI) $\left(\geq 25 \mathrm{~kg} / \mathrm{m}^{2}, 31.6 \%\right.$ vs. $30.9 \%, P=0.501)$ and smoking history $(13.1 \%$ vs. $10.9 \%, P$ 
Table 2. Comparison of Baseline Characteristics in Patients With Non-erosive Reflux Disease, Erosive Reflux Disease and Controls

\begin{tabular}{|c|c|c|c|c|}
\hline & $\begin{array}{c}\text { NERD } \\
(\mathrm{n}=116)\end{array}$ & $\begin{array}{c}\text { ERD } \\
(n=115)\end{array}$ & $\begin{array}{l}\text { Controls } \\
(\mathrm{n}=776)\end{array}$ & $\begin{array}{c}P_{-} \\
\text {value }^{\mathrm{a}}\end{array}$ \\
\hline Age (mean $\pm \mathrm{SD}, \mathrm{yr})$ & $55.8 \pm 8.4$ & $54.2 \pm 9.8$ & $54.9 \pm 8.8$ & 0.384 \\
\hline $\operatorname{Sex}(\mathrm{n}[\%])$ & & & & $<0.001$ \\
\hline Male & $27(23.3)$ & $73(63.5)$ & $297(38.3)$ & \\
\hline Female & $89(76.7)$ & $42(36.5)$ & $479(61.7)$ & \\
\hline $\mathrm{BMI}\left(\right.$ mean $\left.\pm \mathrm{SD}, \mathrm{kg} / \mathrm{m}^{2}\right)$ & $23.7 \pm 3.0$ & $23.9 \pm 2.6$ & $23.7 \pm 2.9$ & 0.373 \\
\hline$<25$ & $84(72.4)$ & $74(64.3)$ & $536(69.1)$ & \\
\hline$\geq 25$ & $32(27.6)$ & $41(35.7)$ & $240(30.9)$ & \\
\hline Cigarette smoking (n [\%]) & $7(6.1)$ & $23(20.2)$ & $84(10.9)$ & 0.002 \\
\hline $\begin{array}{l}\text { Alcohol consumption } \\
\text { (n [\%]) }\end{array}$ & $45(39.8)$ & $74(64.3)$ & $339(43.9)$ & $<0.001$ \\
\hline Nocturnal GERD (n [\%]) & $32(27.6)$ & $22(19.1)$ & $32(4.1)$ & $<0.001$ \\
\hline
\end{tabular}

NERD, nonerosive reflux disease; ERD, erosive reflux disease; BMI, body mass index GERD, gastroesophageal reflux disease.

${ }^{a}$ Chi-square test and ANOVA.

$=0.346$ ) between GERD and control groups (Table 1). Patients were categorized into 3 groups according to GERD symptoms and endoscopic findings: 115 individuals into ERD group (LA classification A to D in endoscopic examination), 116 individuals into NERD group (GERD symptoms and normal or minimal change on endoscopy), and 776 individuals into the control group. There were no significant differences in age among the 3 groups. The proportion of women was higher in the NERD and control groups, whereas the proportion of men was higher in the ERD group $(P<0.001)$. No significant differences in BMI were found among 3 groups (BMI $\geq 25,27.6 \%$ in NERD group vs. $35.7 \%$ in ERD group vs. $30.9 \%$ in the control group, $P=0.373$ ).

A history of smoking was more common in the ERD group (20.2\%) than the NERD group $(6.1 \%, P=0.002)$ (Table 2$)$. Similarly a history of alcohol consumption was more common in the ERD group (64.3\%) than NERD group $(39.8 \%, P<0.001)$.

\section{Prevalence of High Risk for Obstructive Sleep Apnea}

We found 220 patients at high risk for OSA (21.8\%). The proportion of subjects with high risk for OSA was significantly higher in the GERD group (28.2\%) than in the control group (20.4\%, $P=0.036)$. Among the 3 groups, a significantly higher number of patients in the NERD group (32.8\%) had high risk for OSA than the ERD group (20.9\%) and controls (20.4\%, $P=0.010$ ) (Fig. 2). The number of subjects at high risk for OSA was not significantly different between the ERD group and

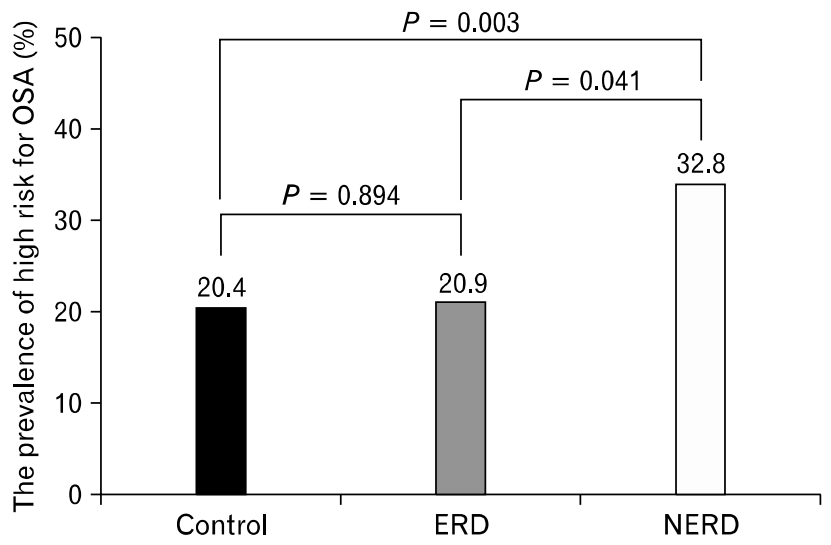

Figure 2. The prevalence of patients at high risk for obstructive sleep apnea (OSA) among non-erosive reflux disease (NERD), erosive reflux disease (ERD) and control groups. In all, $32.8 \%$ patients in the NERD group, $20.9 \%$ in the ERD group and $20.4 \%$ in the control group had high risk for OSA $(P=0.010)$.

controls. $(P=0.894)$. Typical GERD symptoms of more than once a week were found in $24.3 \%$ (28/115) of patients with ERD, but the presence $(21.4 \%)$ or absence of $(20.7 \%)$ GERD symptoms was not associated with high risk for OSA.

\section{Risk factors for Obstructive Sleep Apnea}

On univariate analysis, high risk of OSA was related to age $\geq 55$ years $(P<0.001)$, a BMI of $\geq 25 \mathrm{~kg} / \mathrm{m}^{2}(P<0.001)$, nocturnal GERD $(P=0.050)$ and NERD $(P<0.001)$. However, ERD was not related to high risk of OSA $(P=0.894)$. Sex, a history of smoking, and alcohol consumption were not related to high risk of OSA. On multivariate analysis, age $\geq 55$ years (odds ratio [OR], 1.83; $P<0.001$ ), a $\mathrm{BMI} \geq 25 \mathrm{~kg} / \mathrm{m}^{2}$ (OR, 2.76; $P<0.001)$ and NERD (OR, 1.82; $P=0.011)$ were independent risk factors related to high risk of OSA (Table 3 ).

\section{Nocturnal Gastroesophageal Reflux Disease and Obstructive Sleep Apnea}

Of the 231 subjects with GERD, nocturnal GERD was observed in 54 (23.4\%). Nocturnal GERD was more frequent in the NERD group (27.6\%) than in the ERD group (19.1\%, $P<$ $0.001)$. In the 116 subjects with NERD, high risk of OSA occurred more frequently in patients with nocturnal GERD (46.9\%) than in those who did not $(27.4 \%, P=0.046)$. However, for the 115 patients with ERD, there was no significant difference in the rates of high risk for OSA according to nocturnal GERD (18.2\% vs. $21.5 \%, P=0.740$ ) (Fig. 3 ). While age $\geq 55$ years was an independent risk factor for high risk of OSA in the ERD group 
Table 3. Risk Factors for Obstructive Sleep Apnea Based on Univariate and Multivariate Logistic Regression Analyses

\begin{tabular}{|c|c|c|c|c|c|}
\hline & \multirow{2}{*}{$\begin{array}{c}\text { Number (\%) of } \\
\text { high risk for OSA }\end{array}$} & \multicolumn{2}{|c|}{ Univariate analysis } & \multicolumn{2}{|c|}{ Multivariate analysis } \\
\hline & & OR $(95 \% \mathrm{CI})$ & $P$-value & OR (95\% CI) & $P$-value \\
\hline \multicolumn{6}{|l|}{ Age (yr) } \\
\hline$<55$ & $80 / 496(16.1)$ & 1 & & 1 & \\
\hline$\geq 55$ & $140 / 511(27.4)$ & $1.96(1.44-2.66)$ & $<0.001$ & $1.83(1.33-2.51)$ & $<0.001$ \\
\hline \multicolumn{6}{|l|}{ Sex } \\
\hline Male & 93/397 (23.4) & 1 & & & \\
\hline Female & $127 / 610(20.8)$ & $0.86(0.63-1.16)$ & 0.322 & & \\
\hline \multicolumn{6}{|c|}{$\operatorname{BMI}\left(\mathrm{kg} / \mathrm{m}^{2}\right)$} \\
\hline$<25$ & $111 / 691(16.1)$ & 1 & & 1 & \\
\hline$\geq 25$ & $109 / 316(34.5)$ & $2.82(2.07-3.85)$ & $<0.001$ & $2.76(2.01-3.78)$ & $<0.001$ \\
\hline \multicolumn{6}{|c|}{ Cigarette smoking $^{a}$} \\
\hline No & $197 / 889(22.2)$ & 1 & & & \\
\hline Yes & $21 / 114(18.4)$ & $0.79(0.48-1.31)$ & 0.363 & & \\
\hline \multicolumn{6}{|c|}{ Alcohol consumption $^{\mathrm{a}}$} \\
\hline No & $115 / 543(21.2)$ & 1 & & & \\
\hline Yes & $103 / 458(22.5)$ & $1.08(0.80-1.46)$ & 0.617 & & \\
\hline \multicolumn{6}{|c|}{ Nocturnal GERD Sx } \\
\hline No & $194 / 921(21.1)$ & 1 & & 1 & \\
\hline Yes & $26 / 86(30.2)$ & $1.63(1.00-2.65)$ & 0.050 & $1.55(0.90-2.66)$ & 0.112 \\
\hline \multicolumn{6}{|l|}{ Group } \\
\hline Control & $158 / 776(20.4)$ & 1 & & 1 & \\
\hline ERD & $24 / 115(20.9)$ & $1.03(0.64-1.68)$ & 0.894 & $0.93(0.56-1.55)$ & 0.789 \\
\hline NERD & $38 / 116(32.8)$ & $1.91(1.25-2.92)$ & $<0.001$ & $1.82(1.15-2.90)$ & 0.011 \\
\hline
\end{tabular}

${ }^{a}$ Missing values: cigarrette smoking $(\mathrm{n}=4)$ and alcohol consumption $(\mathrm{n}=6)$.

OSA, obstructive sleep apnea; BMI, body mass index; GERD, gastroesophageal reflux disease; Sx, symptom; ERD, erosive reflux disease; NERD, non-erosive reflux disease.

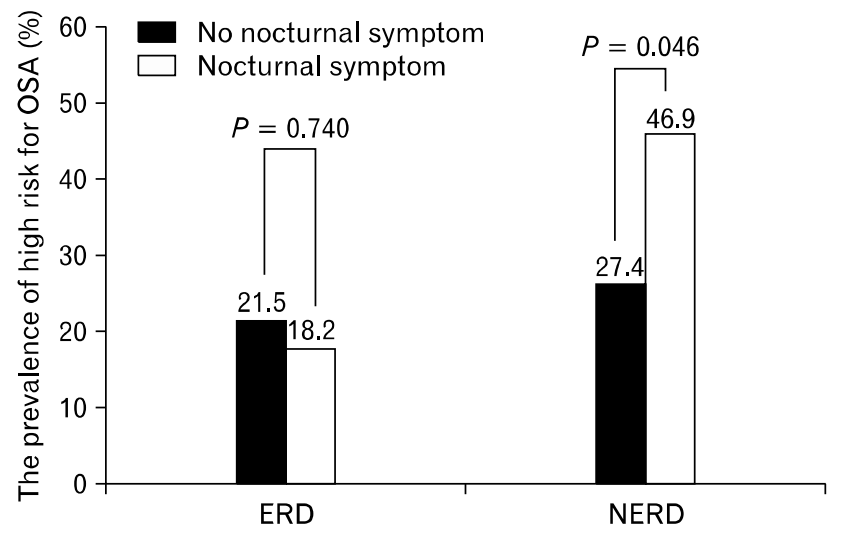

Figure 3. Comparison of obstructive sleep apnea (OSA) risk between patients with non-erosive reflux disease (NERD) and those with erosive reflux disease (ERD) based on nocturnal gastroesophageal reflux disease (GERD). In the NERD group, high risk for OSA occurred more frequently in patients with nocturnal GERD. However, in the ERD group, there was no significant difference in the rate of high risk for OSA.
(OR, 6.51; 95\% confidence interval $[\mathrm{CI}], 2.03-20.83 ; P=$ $0.002)$, nocturnal GERD was the only independent risk factor in the NERD group (OR 2.97; 95\% CI, 1.19-7.84; $P=0.019$ ).

\section{Discussion}

This study shows that GERD can be associated with OSA in the general population. Recent studies have suggested that symptomatic GERD and OSA are closely related. However, the exact causative relationship remains unclear. GERD occurs in up to $60 \%$ of OSA patients; comparatively, it occurs in only $20 \%$ of the general population. ${ }^{14-16}$ In addition, several studies showed that OSA was more common in GERD patients than in the general population. ${ }^{3,17,18}$ A recent study showed that the prevalence of OSA was higher over $10 \%$ in GERD patients compared with general population. ${ }^{3}$ However, other studies did not use a questionnaire and endoscopy to evaluate GERD. Furthermore, some of the patients with other gastrointestinal disease such as gastric ulcer, duodenal ulcer, or gastric cancer may have been included in the 
GERD group. In our study, we performed endoscopy in all study participants and excluded patients who were diagnosed with other gastrointestinal disorders.

In this study, we found that an increased risk for OSA was more frequent in patients with NERD than in those with ERD and controls. No difference in high risk for OSA was found between ERD patients and controls. In contrast with the findings of our study, another study in Egyptian patients found that pulmonary manifestations were significantly higher in ERD patients than in NERD patients. ${ }^{19}$

Although we report an association between high risk of OSA and NERD, we did not identify any obvious explanation for the mechanism of this association. We hypothesize that NERD patients may be at risk of extraesophageal symptoms. Most studies have shown that NERD patients have other digestive symptoms, such as functional dyspepsia and irritable bowel syndrome, as well as non-digestive symptoms, such as chest pain, urinary symptoms, and mood disorder with a higher frequency than that observed in ERD patients. ${ }^{20-22}$ An observational study demonstrated that non-digestive symptoms, including chest pain, dyspnea, cough, urinary symptoms, and sleep disturbance, were more frequent in $\mathrm{pH}$-positive NERD patients compared to that in ERD patients. ${ }^{22}$ In addition, sleep dysfunction and anxiety were higher in NERD patients compared with controls. ${ }^{23}$

There is insufficient evidence for a causal relationship between GERD and OSA. One explanation for this is that both disorders have common risk factors, such as obesity and alcohol consumption, and the association between the two disorders is complex. Treatments used for GERD or OSA often improve the symptoms of the other. Nasal continuous positive airway pressure treatment for OSA improves the symptoms of GERD. ${ }^{24,25}$ Proton pump inhibitor treatment reduces the obstructive events and improves the apnea hypopnea index in OSA patients. ${ }^{26,27}$ In patients with OSA, intrathoracic pressure is increased negatively during an apnea. In addition, hyperventilation after sleep apnea is related to the mechanism of GERD. The connection between the diaphragm and lower esophageal sphincter through the phrenoesophageal ligament is considered the mechanism of GERD in OSA patients. ${ }^{2}$ Conversely, nocturnal acid regurgitation, repetitive microaspiration of gastric acid and vagal reflex may induce OSA in GERD patients. Many patients with GERD have nocturnal reflux symptoms, because sleep itself leads to proximal migration of gastric acid and aspiration into the tracheal-bronchial tree. ${ }^{28}$ The proximal migration of refluxed gastric contents and microaspiration of acid during sleep can cause inflammation and edema of the up- per airway, as well as bronchoconstriction, thereby predisposing to OSA. The refluxed gastric acid in the distal esophagus in GERD also triggers a vagal reflex that can facilitate bronchospasm. ${ }^{29}$ However, these hypotheses of the OSA pathogenesis in GERD need to be investigated.

Nocturnal GERD is considered to have a greater risk for respiratory complications including OSA. ${ }^{3,30}$ According to previous studies, nocturnal symptoms of GERD are more common in patients with OSA and may be improved by treatment with nasal continuous positive airway pressure. ${ }^{25} \mathrm{~A}$ recent study also showed that having persistent nocturnal symptoms of GERD is linked to recent development of OSA symptoms. ${ }^{30}$ In our study, subjects with nocturnal GERD in the NERD group were more frequently at high risk for OSA than those in the ERD group. The ERD group in our study included some subjects without typical reflux symptoms, while the NERD group did not. We did not investigate sleep disturbance in our subjects. Sleep disturbance is known to occur more frequently in NERD than in ERD. ${ }^{31-33}$ These factors may influence the relationship between nocturnal symptoms of GERD and high risk for OSA in the NERD group.

We acknowledge there are limitations in this study. First, the definition of high risk for OSA was not based on objective measurement such as a polysomnography but on a subjective, self-reported questionnaire. We were unable to perform a polysomnography in many of the study participants. Although polysomnography is the standard diagnostic tool used to evaluate OSA, the BQ has been frequently used as the screening test for OSA in large-scale studies. ${ }^{5}$ The sensitivity and specificity of the BQ results varied, perhaps because of the different cutoff values for OSA diagnosis. A recent validation study reported that the sensitivity was $86 \%$, and specificity was $95 \%$ when a high-risk OSA category was defined by the BQ predicted an apnea-hypopnea index $\geq 5 .{ }^{10} \mathrm{~A}$ validation study for Korean version of the BQ showed excellent internal consistency and reliability. High-risk groups for OSA defined by the Korean BQ predicted an apnea-hypopnea index $\geq 5$ with a sensitivity of $69 \%$ and a specificity of $83 \% .{ }^{12}$ Second, we diagnosed and classified GERD groups using the questionnaire for GERD symptoms and endoscopic findings without esophageal $\mathrm{pH}$ monitoring. This might have led to NERD being over-diagnosed because functional dyspepsia, esophageal motility disorder, and other gastrointestinal disorders were included in the NERD group. However, we attempted to distinguish GERD more accurately by defining reflux symptoms only when they occurred at least once a week or more. We also performed gastroduodenal endoscopy in all subjects to exclude 
other gastrointestinal diseases. Third, patients with severe GERD (LA classification C or D) accounted for only a minority of patients in our study because we included many subjects from the health promotion center.

In conclusion, high risk for OSA developed more frequently in GERD patients compared with healthy controls. NERD, age $\geq 55$ years, and a high BMI might be related to high risk for OSA. The unclear mechanism of the association between OSA and GERD calls out for further studies by using more accurate diagnostic tools (e.g., esophageal pH monitoring for GERD and polysomnography for OSA).

\section{Acknowledgements}

The statistical consultation was supported by Catholic Research Coordinating Center of the Korea health 21 R \& D Project (A070001), Ministry of Health \& Welfare Republic of Korea.

\section{References}

1. Jung HK. Epidemiology of gastroesophageal reflux disease in Asia: a systematic review. J Neurogastroenterol Motil 2011;17:14-27.

2. Demeter $\mathrm{P}, \mathrm{Pap} \mathrm{A}$. The relationship between gastroesophageal reflux disease and obstructive sleep apnea. J Gastroenterol 2004;39:815-820.

3. Emilsson OI, Janson C, Benediktsdóttir B, Júlíusson S, Gíslason T. Nocturnal gastroesophageal reflux, lung function and symptoms of obstructive sleep apnea: Results from an epidemiological survey. Respir Med 2012;106:459-466.

4. Ing AJ, Ngu MC, Breslin AB. Obstructive sleep apnea and gastroesophageal reflux. Am J Med 2000;108(suppl 4a):120S-125S.

5. Ahmadi N, Chung SA, Gibbs A, Shapiro CM. The Berlin questionnaire for sleep apnea in a sleep clinic population: relationship to polysomnographic measurement of respiratory disturbance. Sleep Breath 2008;12:39-45.

6. Cho YS, Choi MG, Jeong JJ, et al. Prevalence and clinical spectrum of gastroesophageal reflux: a population-based study in Asan-si, Korea. Am J Gastroenterol 2005;100:747-753.

7. Jeong JJ, Choi MG, Cho YS, et al. Chronic gastrointestinal symptoms and quality of life in the Korean population. World J Gastroenterol 2008;14:6388-6394.

8. Oh JH, Kim TS, Choi MG, et al. Relationship between Psychological Factors and Quality of Life in Subtypes of Gastroesophageal Reflux Disease. Gut Liver 2009;3:259-265.

9. Oh JH, Choi MG, Park JM, et al. The clinical characteristics of gastroesophageal reflux disease in patients with laryngeal symptoms who are referred to gastroenterology. Dis Esophagus 2013;26:465-469.

10. Sharma SK, Vasudev C, Sinha S, Banga A, Pandey RM, Handa KK. Validation of the modified Berlin questionnaire to identify patients at risk for the obstructive sleep apnoea syndrome. Indian J Med Res 2006;124:281-290.

11. Netzer NC, Stoohs RA, Netzer CM, Clark K, Strohl KP. Using the
Berlin Questionnaire to identify patients at risk for the sleep apnea syndrome. Ann Intern Med 1999;131:485-491.

12. Kang K, Park KS, Kim JE, et al. Usefulness of the Berlin Questionnaire to identify patients at high risk for obstructive sleep apnea: a population-based door-to-door study. Sleep Breath 2013;17:803-810.

13. Lundell LR, Dent J, Bennett JR, et al. Endoscopic assessment of oesophagitis: clinical and functional correlates and further validation of the Los Angeles classification. Gut 1999;45:172-180.

14. Morse CA, Quan SF, Mays MZ, Green C, Stephen G, Fass R. Is there a relationship between obstructive sleep apnea and gastroesophageal reflux disease? Clin Gastroenterol Hepatol 2004;2:761-768.

15. Valipour A, Makker HK, Hardy R, Emegbo S, Toma T, Spiro SG. Symptomatic gastroesophageal reflux in subjects with a breathing sleep disorder. Chest 2002;121:1748-1753.

16. Locke GR 3rd, Talley NJ, Fett SL, Zinsmeister AR, Melton LJ 3rd. Prevalence and clinical spectrum of gastroesophageal reflux: a population-based study in Olmsted County, Minnesota. Gastroenterology 1997;112:1448-1456.

17. Guda N, Partington S, Vakil N. Symptomatic gastro-oesophageal reflux, arousals and sleep quality in patients undergoing polysomnography for possible obstructive sleep apnoea. Aliment Pharmacol Ther 2004;20:1153-1159.

18. Gislason T, Janson C, Vermeire P, et al. Respiratory symptoms and nocturnal gastroesophageal reflux: a population-based study of young adults in three European countries. Chest 2002;121:158-163.

19. Maher MM, Darwish AA. Study of respiratory disorders in endoscopically negative and positive gastroesophageal reflux disease. Saudi J Gastroenterol 2010;16:84-89.

20. De Vries DR, Van Herwaarden MA, Baron A, Smout AJ, Samsom M. Concomitant functional dyspepsia and irritable bowel syndrome decrease health-related quality of life in gastroesophageal reflux disease. Scand J Gastroenterol 2007;42:951-956.

21. Jung HK, Halder S, McNally M, et al. Overlap of gastro-oesophageal reflux disease and irritable bowel syndrome: prevalence and risk factors in the general population. Aliment Pharmacol Ther 2007;26: 453-461.

22. Zimmerman J, Hershcovici T. Non-esophageal symptoms cannot differentiate between erosive reflux esophagitis and non-erosive reflux disease in a referred population. Scand J Gastroenterol 2011;46: 797-802.

23. Kim JY, Kim N, Seo PJ, et al. Association of sleep dysfunction and emotional status with gastroesophageal reflux disease in Korea. J Neurogastroenterol Motil 2013;19:344-354.

24. Kerr P, Shoenut JP, Millar T, Buckle P, Kryger MH. Nasal CPAP reduces gastroesophageal reflux in obstructive sleep apnea syndrome. Chest 1992;101:1539-1544.

25. Green BT, Broughton WA, O'Connor JB. Marked improvement in nocturnal gastroesophageal reflux in a large cohort of patients with obstructive sleep apnea treated with continuous positive airway pressure. Arch Intern Med 2003;163:41-45.

26. Zamagni M, Sforza E, Boudewijns A, Petiau C, Krieger J. Respiratory effort. A factor contributing to sleep propensity in patients with obstructive sleep apnea. Chest 1996;109:651-658.

27. Wasilewska J, Semeniuk J, Cudowska B, Klukowski M, Debkowska K, Kaczmarski M. Respiratory response to proton pump inhibitor treatment in children with obstructive sleep apnea syndrome and gas- 
troesophageal reflux disease. Sleep Med 2012;13:824-830.

28. Orr WC, Heading R, Johnson LF, Kryger M. Review article: sleep and its relationship to gastro-oesophageal reflux. Aliment Pharmacol Ther 2004;20(suppl 9):39-46.

29. Harding SM. Gastroesophageal reflux, asthma, and mechanisms of interaction. Am J Med 2001;111(suppl 8A):8S-12S.

30. Emilsson ÃsI, Bengtsson A, Franklin K, et al. Nocturnal gastro-oesophageal reflux, asthma and symptoms of OSA: a longitudinal, general population study. Eur Respir J 2013;41:1347-1354.
31. Yi $\mathrm{CH}, \mathrm{Hu} \mathrm{CT}$, Chen CL. Sleep dysfunction in patients with GERD: erosive versus nonerosive reflux disease. Am J Med Sci 2007;334: 168-170.

32. Kim J, Kim N, Seo P, et al. Association of sleep dysfunction and emotional status with gastroesophageal reflux disease in Korea. J Neurogastroenterol Motil 2013;19:344-354.

33. Ju G, Yoon IY, Lee SD, Kim N. Relationships between sleep disturbances and gastroesophageal reflux disease in Asian sleep clinic referrals. J Psychosom Res 2013;75:551-555. 